Alexandra Spalek

Universitat Pompeu Fabra

\title{
LOS DICCIONARIOS DE APRENDIZAJE Y LA REPRESENTACIÓN LEXICOGRÁFICA DE LA TRANSPOSICIÓN SEMÁNTICA EN ALGUNOS VERBOS
}

\section{Introducción}

La representación lexicográfica de la polisemia léxica procedente de los usos figurados ha sido tratada teóricamente por muchos lexicógrafos, como por ejemplo De Hoyos (1996), Porto Dapena (2002) o Battaner (2006), y ha sido plasmada y marcada de diversas maneras en distintos diccionarios, a veces explicitando el criterio y a veces más bien ocultando las bases teóricas sobre las que se elaboraba y marcaba. En los últimos años, sin embargo, han aumentado las discusiones acerca de las dificultades que sigue presentando el empleo de una marca de sentido figurado para las voces polisémicas. Dichas discusiones han puesto en entredicho la relevancia de este tipo de marcas, llevando finalmente a la supresión generalizada liderada por diccionarios de gran importancia como el Diccionario de la Real Academia Española (DRAE) en su edición del año 2001.

Paralelamente ha crecido el interés por las dificultades que presenta el lenguaje figurado en el ámbito de la adquisición de lenguas extranjeras trayendo consigo que especialmente los diccionarios monolingües de aprendizaje se esforzaran cada vez más por recoger información acerca de metáforas, intentando así contribuir a la ampliación del vocabulario del estudiante extranjero, como se observa en el caso del Macmillan English Dictionary for Advanced Learner. Dicho diccionario comenzó a incorporar en su edición del año 2002 los tal llamados Metaphor Boxes que informaban a sus usuarios de metáforas conceptuales frecuentes, hasta finalmente terminar añadiendo en el año 2007 una sección teórico-práctica de cuatro páginas a fin de dar cuenta de la importancia y de la frecuencia del proceso de creación de nuevo vocabulario basado en la derivación semántica figurada a partir del sentido recto de una voz.

Generalmente se puede decir que la representación sincrónica de la polisemia se plasma en artículos lexicográficos de varias acepciones correspondientes a un solo lema. Dependiendo de la distancia semántica patente entre los distintos usos de la unidad léxica se distinguen más o menos acepciones entre las cuales hasta hace relativamente poco se solían resaltar las acepciones metafóricas con marcas como figurado, metafóricamente, por alusión, etc., que concienciaban al usuario del uso figurado de una acepción determinada. No obstante, como observaron Borràs y Torner (2006) este tipo de marcas ha desaparecido casi por completo en la última edición del Diccionario de la Real Academia Española quedando en apenas 295 indicaciones acerca de los usos figurados en comparación con las 17000 acepciones marcadas con fig. en la edición del año 1992. Con dicha supresión de la marca de transposición semántica el DRAE se ha hecho eco de las tendencias actuales que tachan el uso de estas marcas de inapropiado para diccionarios sincrónicos. Y aunque la decisión no se justifica explícitamente en el prólogo de la nueva edición del DRAE, se sobreentiende que la marca no fue considerada lo suficientemente informativa o clara para los usuarios de un diccionario académico, siendo estos principalmente los hablantes nativos o distintos estudiosos del español. Sin embargo, cabe plantearse qué ocurre en el caso de los diccionarios de aprendizaje cuyos usuarios, lejos de conocer todas las exten- 
siones semánticas de una voz polisémica, se enfrentan a la necesidad constante de ampliar su reducido vocabulario, conocer sus usos y memorizarlos. De modo que el objetivo del presente estudio ha sido determinar si la información conceptual que se esconde tras los verbos polisémicos con extensiones figuradas permite una representación lexicográfica más eficaz.

Nuestro estudio se ha centrado fundamentalmente en los verbos, pues son los elementos predicadores, seleccionadores de argumentos, por excelencia. El grupo de verbos tratado en el presente estudio ha surgido de unas observaciones hechas por Ignacio Bosque (2004) en la introducción al diccionario combinatorio del español, REDES. La particularidad de estos verbos es que muestran transposición semántica claramente observable en su combinatoria. Se trata exclusivamente de verbos denominales, lo cual implica que sean verbos de pleno valor semántico, muy precisos en cuanto a los procesos que describen y consecuentemente concretos en sus usos rectos. Asimismo destaca como característica general que los verbos estudiados son bien verbos de movimiento o bien descriptores de estados o procesos propiamente físicos. Para este estudio preliminar nuestra atención se ha centrado únicamente en verbos identificados por el Diccionario de la Real Academia Española como verbos construidos morfológicamente en español, prescindiendo por tanto de verbos más propiamente etimológicos, cuyo significado construido en otras lenguas nos obligaría a ampliar el análisis de las relaciones semánticas. Limitada así la muestra, las voces analizadas fueron las siguientes: abordar, acariciar, acarrear, bordear, destapar, embarcar, empañar, hilvanar y planear. ${ }^{1}$

\section{El léxico y sus entramados conceptuales}

Supongamos, a modo de aproximación, que un estudiante extranjero conoce perfectamente los equivalentes en su idioma de las palabras castellanas acariciar, gato y proyecto. No cabe duda de que será capaz de entender y componer por sus propias fuerzas la combinación acariciar un gato. Es posible que entienda sin mayores problemas la combinación metafórica «El viento acariciaba su pelo», pero difícilmente entendería la construcción acariciar un proyecto, pues, aunque se trata de un argumento habitual para dicho verbo polisémico, proyecto no es un argumento que se pueda obtener a través de un ejercicio de lógica o mediante una descripción espontánea de paradigmas extralingüísticos. Observamos pues que el verbo acariciar se combina con dos tipos de argumentos muy distintos, que a primera vista carecen de relación alguna, a saber: argumentos físicos y argumentos abstractos. Consultando el DRAE en su versión actual accesible en línea vemos que la representación lexicográfica distingue entre cuatro acepciones diferentes. No obstante, se percibe un salto semántico considerable entre las primeras tres acepciones y la última. Y es esta la definición que da cuenta de usos de tipo acariciar un proyecto, que tanto podrían sorprender a un estudiante extranjero del español, pues como hemos mencionado no parece reflejar una transposición semántica continuada, y la relación semántica entre las primeras tres acepciones y la cuarta se vuelve opaca e incluso puede parecer arbitraria. Dicho de forma más informal: la cuarta acepción nos sorprende, porque le hemos perdido la pista:

\footnotetext{
${ }^{1}$ A propósitos del análisis se observaron cien concordancias para cada verbo. Para la recopilación de datos se utilizó dos corpus relativamente distintos, accesibles a través del sistema de consulta de corpus Word Sketch Engine (WSE) (www.sketchengine.co.uk/), así como el corpus dirigido a estudiantes de español como lengua extranjera de Mark Davis (CdE) (www.corpusdelespanol.org/).
} 


\section{acariciar}

1. tr. Hacer caricias.

2. tr. Tratar a alguien con amor y ternura.

3. tr. Dicho de una cosa: Tocar, rozar suavemente a otra.

4. tr. Complacerse en pensar algo con deseo o esperanza de conseguirlo o llevarlo a cabo.

Algo parecido ocurre en el caso del diccionario SALAMANCA, donde además curiosamente una de las acepciones figuradas del verbo se recoge conjuntamente con la acepción recta en la que esta se origina, como observamos en la primera de las tres acepciones:

\section{acariciar}

verbo transitivo, prnl.

1 Hacer < una persona o una cosa> caricias [a otra persona o a un animal]: El viento acariciaba su hermoso pelo. Me gusta acariciar a los gatos. Los amantes se acariciaban continuamente.

Verbo transitivo

1 Tocar <una persona> [una cosa] suavemente: Acariciaba la tela mientras calculaba el precio de la falda y la chaqueta.

2 Pensar < una persona> en la realización de [una cosa]: Acariciar la idea de marcharse a América.

Finalmente el CLAVE en su versión actual en línea, hace amagos de paliar la posible sorpresa ejemplificando con más detalle la combinatoria del verbo en su acepción metafórica:

acariciar (v.)

1 Hacer caricias o rozar suavemente con la mano: ¿Puedo acariciar a tu perro?

2 Referido a una cosa, tocarla o rozarla suavemente otra: Las olas acariciaban la orilla.

3 Referido a un proyecto o a una idea, pensar en su consecución o en su ejecución:

Acariciaba la idea de ganar la carrera.

Esta formulación deja parcialmente clara la diferencia en cuanto a la selección argumental indicando explícitamente que la acepción 2 se combina con cosas físicas ("referido a una cosa") mientras que la acepción 3 va restringida a sustantivos abstractos, como proyecto o idea, aunque habría que mencionar la ausencia de otros argumentos posibles y frecuentes como gol, victoria, etc. No obstante, también falla en dar cuenta de la conexión semántica entre las primeras dos acepciones y la tercera.

En definitiva, ninguno de los tres diccionarios alerta satisfactoriamente al usuario de la transposición que sufre el significado del verbo en relación a los argumentos que escoge. Ello puede dar al estudiante una idea de que las distintas acepciones de voces polisémicas como acariciar, acarrear, bordear, etc. son independientes. Una visión que a su vez impide por completo que el estudiante forje un concepto semántico holístico que le pudiera ayudar en un futuro a descodificar las distintas extensiones, aunque éstas no le resulten del todo familiares.

Sin embargo, las extensiones metafóricas representan un mecanismo de creación de nuevos significados muy habitual, y por ello forman intrínsecamente parte del proceso de 
aprendizaje de una lengua extranjera. Hay que recordar al respecto que mientras los hablantes nativos, que conocen de manera natural gran parte de la combinatoria de un verbo polisémico, no incurren en el error de interpretar las acepciones figuradas (acariciar un gol) literalmente, los estudiantes tienden en primer lugar siempre hacia una interpretación literal, como ha sido observado por Philip (2006). Además estudios de Siepmann (2005) reflejan que un estudiante avanzado de una lengua extranjera puede tener un perfecto dominio léxico-gramatical que le baste para cubrir todas sus necesidades comunicativas, no obstante, habitualmente no llega ni de lejos a la competencia léxico-combinatoria de los hablantes nativos. Creemos por tanto que ser consciente, en cierta medida, del trasfondo cognitivo que se refleja en la combinatoria metafórica puede facilitar la adquisición de nuevo vocabulario. La metáfora conceptual traza aquí un puente entre los distintos usos verbales: el más literal o recto y el uso figurado o metafórico. No se trata meramente de una figura estilístico-retórica, sino, mucho más, de un mecanismo de naturaleza cognitivo-conceptual que nos permite seguir la abstracción de los verbos y que se manifiesta en usos como acariciar ideas, acarrear problemas, empañar la felicidad. Dicha conciencia puede ayudar al estudiante de español y contribuir a que las combinaciones metafóricas no le resulten tan arbitrarias. Y como es bien sabido un mejor entendimiento a su vez facilita el proceso de memorización.

Según Lakoff y Johnson (1986) la metáfora conceptual encuentra sus raíces en las experiencias físicas y no representa una mera asignación arbitraria de características diversas. De este modo nuestro cuerpo como entidad físicamente bien delimitada se convierte en referente para entrar en contacto con muchas de nuestras experiencias no físicas, y nos permite estructurarlas y por consiguiente referirnos a ellas (Gibbs y Steen, 1997). Expresamos emociones y acontecimientos de carácter mental a través de metáforas que hacen referencia a vivencias físicas (acarrear problemas, hilvanar un discurso, etc.). Es la característica de proximidad e inmediatez, propia de los acontecimientos físicos, la que nos acerca a los dominios abstractos y los hace más fácilmente conceptualizables. Parece pues que la expresión linguiística resultante de un proceso de cognición abstracto muestra carácter fundamentalmente metafórico, siendo este el nexo que establece la relación entre dos dominios ${ }^{2}$ intrínsicamente distintos. Las experiencias físicas son compartidas por una comunidad lingüístico-cultural y es ésta la base de la metáfora. A grosso modo se puede decir que la metáfora viene a representar, a modo de abreviatura conceptual, un conjunto de experiencias compartidas por los hablantes consideradas prototípicas o predominantes para ciertos conceptos. Dicho conjunto de características constituye un puente en términos de semejanza de procesos o estructuras entre dos conceptos que carecen de semejanza intrínseca real. Y es precisamente en términos de proyección conceptual, gracias a las experiencias compartidas, cómo codificamos y descodificamos extensiones semánticas con fundamento metafórico. Intuimos así que las combinaciones metafóricas no se deben al azar, sino que son frutos de procesos cognitivos basados en la metaforización. De ahí que la metáfora nos sirve de vehículo puente entre las bases empíricas y las realidades abstractas. Observamos entonces que gracias a la metáfora conceptual podemos establecer una relación entre los siguientes dos usos:

\footnotetext{
2 Según Langacker (Langacker, 1987: 488) dominio se define como sigue: «A coherent area of conceptualization relative to which semantic units may be characterized. Three-dimensional space, smell, color, touch sensation, etc. are basic domains. A concept or conceptual complex of any degree of complexity can funcion as an abstract domain (e.g. the human body, the rules of chess, a kinship network).»
} 
(1) El granjero acarrea el grano.

(2) El cambio probablemente les acarrearía desajustes económicos.

Sin prestar ahora mayor atención a los cambios de tipo de argumentos con los que se combina el verbo en su acepción figurada, vemos que acciones que resultan desagradables, molestas o fastidiosas son dotadas de la propiedad peso o, quizás, cabría decir que predomina en ellas la propiedad peso. Dicho de otro modo, podemos afirmar que concebimos las dificultades y los problemas como cargas. Y es esta propiedad física la que predomina en el uso figurado del verbo y permite la combinación con acontecimientos abstractos que concebimos como peso, como las desgracias, posibilitando así razonamientos posteriores más avanzados acerca de dichos conceptos abstractos. Todos los datos por nosotros observados muestran relaciones semánticas recto-figurado similares.

Sirviéndonos de la clasificación de Lakoff y Johnson (1986), que distinguen entre tres tipos de metáforas básicas: ontológicas, estructurales y orientacionales, hemos observado entre nuestros datos principalmente metáforas ontológicas y sólo en un caso nos topamos con una metáfora estructural, mientras no encontramos ninguna metáfora orientacional. En el caso de las metáforas ontológicas se trata de materializaciones de conceptos abstractos que son tratados como entidades físicas:

(3) La convulsión de la Revolución Francesa acarreó nuevos problemas.

(4) El fantasma del cáncer planea por nuestras vidas.

Es un tipo de metáfora conceptual muy básico a partir del cual pueden crearse nuevas metáforas más complejas como las metáforas estructurales, que presentan ciertos conceptos como estructuras, y que a su vez presuponen otras metáforas ontológicas:

(5) Recorrí la casa de Ana Frank tratando de hilvanar los recuerdos del diario leído....

Dentro del grupo de las metáforas ontológicas se diferenció dos subgrupos: el grupo de las metáforas de entidad (acariciar, acarrear, empañarse, planear) y el grupo de las metáforas de recipiente (bordear, abordar, embarcarse, destapar). Para el grupo de las metáforas de entidad observamos como a través de características propias de entidades físicas, como la firmeza (6), el peso (7), la claridad (8) o la existencia física (9), se hace referencia a conceptos abstractos, como la economía, las esperanzas, los sentimientos y se expresan opiniones o juicios de valor:

(6) Ya acariciaba entonces la idea de venir a España.

(7) Ese cambio probablemente les acarrearía desajustes económicos.

(8) Se sentía satisfecho por partida doble y ningún remordimiento le empañaba esa felicidad.

(9) ...las dudas que planean en Wall Street sobre la velocidad de la ralentización de la economía estadounidense

El grupo de las metáforas de recipiente, por el contrario, nos ilustra cómo ciertos conceptos abstractos adquieren la característica de territorialidad física convirtiéndose aparentemente en límites $(10,11)$ y lugares $(12,13)$, y como a través de ello se expresan 
sentimientos y se hace referencia a entidades abstractas difícilmente descriptibles como la edad (10) y los problemas (11), o como se describen estados psicológico-mentales como la falta de información (13):

(10) Bordeo los malditos treinta años.

(11) ... si el problema hubiera sido correctamente abordado en aquel momento.

(12) ....me he embarcado en la divertidísima aventura de aconsejar a alguien...

(13) ...para destapar su guerra encubierta

Finalmente observamos que la metáfora estructural impone una estructura y con ella un orden a un concepto abstracto incorpóreo:

(14) ... recorrí la casa de Ana Frank tratando de hilvanar los recuerdos del diario leído (15) No sin dificultad, consigue hilvanar su discurso

Hallamos tras estas combinaciones la metáfora estructural por la cual creemos que entidades abstractas como recuerdos o discursos tienen textura. La metáfora DISCURSO ES TEJIDO $^{3}$ o TEXTO ES TEJIDO es propia del sistema conceptual de nuestra cultura y no somos capaces de concebir discurso o texto de otra forma. Es especialmente indicado en este caso considerar la etimología de la palabra texto que procedente del latín textus no significa otra cosa que tejido. Se trata de una metáfora de larga historia cultural y ampliamente extendida en distintas lenguas europeas, y por ello hoy ya muy difícilmente es sentida como tal.

A lo largo de nuestro estudio destaca la coaparición de verbos de movimiento o descriptores de procesos físicos junto a argumentos abstractos. Dicha coaparición parece dar sistemáticamente lugar a extensiones verbales metafóricas que tienden a adquirir un valor semántico psicológico y consecuentemente aparecen con frecuencia en contextos que describen tomas de posición, valoraciones u opiniones emocionales. El patrón que parece repetirse puede formularse por tanto de la siguiente manera:

$$
\begin{aligned}
& \left(\text { Verbo }_{\text {proceso_físico }} / \text { Verbo }_{\text {percepción }}\right)+\text { Objeto }_{\text {abstracto }} \\
& \Rightarrow \text { Verbo }_{\text {psicológico_mental }}
\end{aligned}
$$

Consideramos que hay una relación de tipo conceptual entre las distintas acepciones de dichos verbos y que dicha relación se manifiesta en su combinatoria. Se trata de un proceso semántico-cognitivo que va acompañado de una transposición semántica que parece regular. Pensamos que las metáforas identificadas explican con mayor claridad el proceso conceptual que subyace a las combinaciones aquí estudiadas y por tanto coincidimos con Sweetser (1991: 20) en que sólo a través del estudio detallado de las proyecciones metafóricas implícitas en nuestro tratamiento cognitivo y lingüístico de conceptos mentales podemos entender la razón por la cual ciertos verbos que describen procesos físicos son fuente sistemática para nuevo vocabulario particularmente perteneciente a áreas psicológico-mentales.

\footnotetext{
${ }^{3}$ En la literatura acerca de la metáfora cognitiva las mayúsculas en fuente reducida se utilizan para denotar una metáfora conceptual.
} 


\section{Pautas para la representación lexicográfica}

Como se ha observado a lo largo de nuestro trabajo la polisemia resultante de los usos metafóricos de un verbo es un proceso de transposición semántica de frecuencia y regularidad considerable. Sabiendo por tanto que se trata de un mecanismo productivo según el cual los hablantes crean nuevos significados léxicos y teniendo en cuenta que dichos significados y sus usos nuevos se basan al menos parcialmente en un conocimiento conceptual compartido por una comunidad lingüístico-cultural, consideramos importante dar cuenta de la relación semántica entre las acepciones literales y sus extensiones. Se trata por tanto de reflejar que existe una relación de base metafórico-conceptual entre combinaciones como acariciar un gato y acariciar una idea. Entender el nexo conceptual latente entre los distintos usos de un verbo, así como comprender una metáfora conceptual frecuente en una lengua, puede esclarecer una amplia red de relaciones semánticas y hacer las condiciones combinatorias más transparentes. Así la dificultad de aprendizaje que imponen las combinaciones que se fundamentan en parte en metáforas conceptuales tal vez pueda ser salvada, al menos parcialmente, a través de una representación más eficaz y sistemática en los diccionarios, recogiendo en primer lugar explícitamente sus argumentos más frecuentes y marcando en segundo lugar su valor figurado. De modo que en beneficio de la sobriedad y nitidez, y dado que los diccionarios de aprendizaje hoy en día intentan tener en cuenta la posibilidad de servir no sólo de obras de referencias, sino también para la codificación, consideramos que la representación de la polisemia regular basada en la metáfora debería encontrarse marcada, sumándonos así a lo expresado por Van der Meer (1999: 203): «If dicctionaries no longer alert learners especially to metaphorically used language they will fail to learn and grasp important information that is automatically generated by the linguistic intuition of the mature native speaker.»

La marca de la transposición semántica se nos hace necesaria como marca de un conocimiento conceptual natural en los hablantes nativos que tiene fuerte influencia en la combinatoria léxica. En oposición a las tendencias actuales por tanto y en acuerdo con Borràs y Torner (2006), que demostraron que la marca del sentido figurado utilizada en el DRAE en su edición del año 1992 superaba ampliamente las fronteras de la información diacrónica albergando importante información semántica y de uso, pensamos que la marca del sentido figurado es necesaria y puede ser empleada con cierta consistencia marcando el origen metafórico de la evolución semántica en los verbos con acepciones figuradas. A nuestro entender se trata no tanto de una marca que indique el modo de lectura («ha de ser comprendido figuradamente»), sino de una marca que esclarezca la relación semántica entre las distintas acepciones de un verbo polisémico haciendo hincapié en el eslabón intermedio en la cadena semántica. Evidentemente dicha marca alberga información diacrónica al dar cuenta de la acepción más básica que ha de preceder a la metafórica, pero no por ello únicamente tiene este carácter. Podemos defender por tanto su uso desde una perspectiva perfectamente sincrónica.

Consideramos además que una marca así concebida impondría cierto orden de acepciones dentro del artículo lexicográfico, que según nos parece, resulta ser el más natural y el más propicio para impulsar la construcción y la comprensión de un concepto linguiístico-cultural. A saber: un orden que parte del significado recto que se caracteriza de la siguiente manera:

- lo más concreto (lo más fácilmente imaginable y palpable)

- lo relacionado con una acción corporal

- lo más preciso y mejor delimitado 
En definitiva, desde los usos más primarios hasta acabar con el uso que, fruto de la abstracción, resulte más apartado de estas características y por ende necesariamente posterior, el uso metafórico. Dicho orden de acepciones de proximidad conceptual nos parece un orden didáctico y por ello sirve a los propósitos de los diccionarios de aprendizaje. Sólo así se puede ayudar a los estudiantes de una lengua extranjera a establecer una red de relaciones semánticas, que naturalmente implica abstracciones y extensiones semánticas. Van der Meer (1999: 196) habla en referencia a ello de etimología sincrónica: «Treating this basic meaning first, as I have claimed, would enhance the non-native learner's awareness of what I then called synchronic etymology: the realisation that meaning may be related to other, more basic meanings.»

Otros métodos aparentemente neutros parecen atomizar una entrada lexicográfica polisémica en detrimento de una comprensión conceptual holística, como por ejemplo el orden según el criterio de la frecuencia, que impide por completo la posibilidad de dar cuenta de una cierta regularidad observable en la creación de nuevos significados metafóricos.

No obstante, elucidar la relación semántica entre las distintas acepciones de un verbo no implica automáticamente un domino perfecto en cuanto a la combinatoria real del verbo. Por ello sería de capital importancia la enumeración de un número de ejemplos relativamente extenso que abarcara los representantes más prototípicos de la clase léxica que constituyen los argumentos que selecciona un verbo en su uso figurado. Es importante que los estudiantes de español como lengua extrajera sepan que se acarician objetivos que deseamos lograr o cumplir, y que ello se haga palpable en una definición, pero tiene al menos la misma importancia que se enumeren los argumentos abstractos que se combinan con el verbo acariciar (idea, proyecto, victoria, gol, triunfo), a fin de dar cuenta de que no todo lo que uno pueda desear, o a lo que aspira se acaricia habitualmente en español (*acariciar la salud). Es esta una cuestión de clases léxicas, como denomina Bosque (2004) las series de grupos de argumentos que son escogidos por los predicados. De esta manera se pone de manifiesto que el verbo acariciar es ciertamente un verbo de percepción física, pues admite combinaciones con cualquier objeto físico, pero también que es un verbo que sirve para describir esperanzas, como ocurre en acariciar una victoria, un plan, etc. Un diccionario de aprendizaje enfocado a la codificación debería recoger dichos grupos de argumentos posibles. La idea de recoger grupos cerrados de argumentos evitaría generalizaciones demasiado amplias mostrando a sus usuarios cuáles son las convenciones lingüísticas, que, como ha sido destacado por Nunberg (1992), son las que determinan lo que se considera idiomático y lo que no. De esta manera contribuiría a concienciar a sus usuarios de que las palabras no se combinan libremente y que muchas combinaciones engloban cierto conocimiento cultural y conceptual, que se da precisamente gracias a una combinación determinada. La comprensión de la diferencia combinatoria, que muestran los verbos analizados, en términos de diferencia semántica de tipo metafórico-conceptual lleva a una comprensión más profunda del concepto y puede ayudar no sólo en el proceso de memorización, es decir de aprendizaje, sino también en la producción activa del estudiante. Pues, como ha sido subrayado por profesores de lenguas extranjeras (Deignan, 2005; Philip, 2006), el hecho de saber identificar y sobre todo utilizar usos figurados es esencial para el empleo de una lengua especialmente para estudiantes avanzados, que han de saber manejarse en el ámbito profesional o universitario.

Nuestra propuesta de pautas útiles para la representación lexicográfica de la sistematicidad observada en la transposición semántica tiene base fundamentalmente conceptual 
y va enfocada principalmente a los usos verbales metafóricos. Consideramos que la marca se ha de utilizar únicamente cuando el significado de un verbo en dependencia de los argumentos que escoge se aleja considerablemente del significado nuclear del uso más literal y cuando la combinación es relevante debido a su frecuencia.

Se trata de una planta de definición natural que ha resultado ser muy apropiada especialmente en cuanto a los estudiantes de lenguas extrajeras. Los ejemplos siguientes representan una posible propuesta de definición, aunque queda reservado para estudios futuros concretar el tipo de marca que pueda resultar más apropiado para diccionarios de aprendizaje, ya que para ello se precisan más estudios acerca de la capacidad de análisis linguístico y de descodificación de marcas por parte de los estudiantes. No obstante, a fin de potenciar la relación semántico-conceptual, nos parece apropiado crear una oposición clara entre el uso recto, fundamentalmente el sentido físico, en oposición al uso figurado. Pues como observamos es la posibilidad de los verbos propiamente físicos de significados muy precisos de utilizarse con argumentos tanto físicos como abstractos, la característica principal que subyace a la transposición semántica en los verbos estudiados.

\section{acariciar}

EN SU USO RECTO

1. Cuando alguien acaricia una cosa o a alguien, lo toca suavemente con cariño: Acarició el gato.

EN SU USO FIGURADO

2. Cuando una cosa acaricia otra cosa la toca o la roza suavemente:

El viento acariciaba su pelo.

3. Cuando alguien acaricia una posibilidad o cualquier resultado feliz, se complace pensando en conseguirlo o llevarlo a cabo imaginándolo tangible y próximo, como el triunfo, un título, un sueño, una idea o un gol:

María acariciaba la idea de ir a estudiar una carrera.

\section{bordear}

EN SU USO RECTO

1. Cuando alguien bordea algo, va por el extremo, el borde o cerca de su límite u orilla: Bordeamos el lago.

2. Cuando algo bordea algo, se halla en su borde u orilla: Las flores bordean el camino.

EN SU USO FIGURADO

3. Cuando una persona bordea una norma o una condición generalmente moral o intelectual se aproxima a ella como si fuera un límite que no quiere traspasar, como la ley, la confrontación, etc.:

Nada más fácil que bordear la ley.

4. Cuando algo o alguien bordea una cifra, cierta edad, o cualquier sujeto cuantificable, se encuentra cerca de este límite numérico, como porcentaje o edad, etc.:

Las ventas peruanas al exterior bordeaban los 3,000 millones de dólares.

Para futuros proyectos y estudios dirigidos a los diccionarios de aprendizaje sería posible incluso plantearse la eventualidad de reflejar relaciones semántico-cognitivas sistemáticas mucho más extensas, como ya ha sido intentado en el Macmillan English Dictionary for Advanced Learner en su publicación del 2002 y 2007. Sería pues plausible 
imaginar, especialmente para los diccionarios electrónicos, que no padecen problemas de espacio, la posibilidad de recoger catálogos de usos lingüístico-conceptuales relacionados como por ejemplo: hilvanar recuerdos, perder el hilo, tejer un discurso, etc., aunque ello exceda el marco de la combinatoria verbal. No obstante, se trata de usos habituales y naturales para los hablantes nativos del castellano, y ser consciente de la productividad semántica de las metáforas puede repercutir positivamente en la adquisición de nuevo vocabulario. Por ello creemos que conviene que los lexicógrafos, y particularmente los lexicógrafos dedicados a diccionarios de aprendizaje, sean conscientes de las regularidades de los fenómenos metafóricos que se reflejan en la polisemia para así poder facilitar tanto la consulta como la adquisición de nuevo vocabulario.

\section{BIBLIOGRAFÍA}

\section{a) Estudios y Artículos consultados}

Battaner, P., Torner, S. (2006): «La polisemia verbal que muestra la lexicografía». En: Actas del II Congreso Internacional de Lexicografía Hispánica. Alicante: Universidad de Alicante.

Borràs, L., Torner, S. (2006): «De Nuevo sobre la Marca Figurado en los Diccionarios». En: Elisenda Bernal, Janet DeCesaris (eds.): Palabra por Palabra. Estudios ofrecidos a Paz Battaner. Barcelona: IULA, Universitat Pompeu Fabra, 33-45.

Bosque, I. (2004): «Combinatoria y significación. Algunas reflexiones». En: Diccionario REDES: Diccionario Combinatorio del Español Contemporaneo (LXXVII-CLXXIV). Madrid: SM.

De Hoyos, J. C. (1999-2000): «La marca de transición semántica: sentido figurado». En: Revista de Lexicografia, 6, 73-105.

Deignan, A. (2005): Metaphor and Corpus Linguistics. Amsterdam: John Benjamins Publishing Company.

Gibbs, R. W., Steen, G. J. (1997): Metaphor in Cognitive Linguistics. Amsterdam: John Benjamin Publishing Copany.

González Pérez, R. (2000-2001): «La marca figurado en los diccionarios de uso». En: Revista de Lexicografía, 7, 77-89.

Kilgarriff, A. (1997): «I don't believe in word senses». En: Information Technology Research Institute Technical Report Series, University of Brighton.

Lakoff, G., Johnson, M. (198677): Metáforas de la vida cotidiana. Madrid: Cátedra.

Moon, R. (2004): «On specifying metaphor: an idea and its implementation». En: International Journal of Lexicography, 17, 2, 195-222.

Nunberg, G., Zaenen, A. (1992): «Systematic polysemy in lexicology and lexicography1». En: UC Berkeley School of Information Geoffrey Nunberg: http://people.ischool.berkeley.edu/ nunberg/Euralex.html (20. 07. 2008)

Philip, G. (2006): «Metaphor, the dictionary, and the advanced learner». En: Alma Mater Digital Library: http://amsacta.cib.unibo.it/archive/00002062/ (20. 07. 2008)

Porto Dapena, J. Á. (2002): Manual de Técnica Lexicográfica. Madrid: Arco.

Porto Dapena, J. Á. (2005-2006): «Fundamentos teóricos y metodológicos para un estudio lexicográfico del verbo asquear». En: Revista de Lexicografía, 12, 209-221. 
Pragglejaz Group (2007): «MIP: a method for identifying metaphorically used words in discourse». En: Metaphor and Symbol, 22, 1, 1-39.

Siepmann, D. (2005): «Collocation, colligation and encoding dictionaries. Part II: Lexicographical aspects». En: International Journal of Lexicography, 19, 1, 1-39.

Sweetser, E. (1991): From etymology to pragmatics. Metaphorical and cultural aspects fo semántica structure. Cambridge: Cambridge University Press.

Van der Meer, G. (1999): «Metaphor and dictionaries: the morass of meaning, or how to get two ideas for one». En: International Journal of Lexicography, 12, 3, 195-208.

\section{b) Fuentes lexicográficas}

Davis, M. (n. d.): Corpus del español. (Brigham Young University) En: Corpus del español: www.corpusdelespanol.org/x.asp (20. 07. 2008)

Diccionarios SM (n.d.): Clave Diccionarios SM. En: Diccionario Clave: http://clave.librosvivos.net/ (20. 07. 2008)

Ediciones SM (2004): REDES Diccionario combinatorio del español contemporáneo. Madrid: Ediciones SM.

Lexicom Lexical Computing (n.d.): Sketch engine. En: Sketch Engine: www.sketchengine.co.uk/ (20. 07. 2008)

Macmillan (2002): Macmillan English Dictionary for Advanced Learners. Oxford: Macmillan.

Macmillan (2007): Macmillan English Dictionary for Advanced Learners. Oxford: Macmillan.

Real Academia Española (1992): Diccionario de la lengua española. (21). Madrid: Espasa-Calpe.

Real Academia Española. Diccionario de la Lengua Española: www.rae.es/rae.html (20. 07. 2008)

Santillana ELE. Diccionario Salamanca de la lengua española: http://fenix.cnice.mec.es/diccionario/ (20. 10. 2008)

\section{ŠOLSKI SLOVARJI IN LEKSIKOGRAFSKA PREDSTAVITEV SEMANTIČNEGA PRENOSA PRI NEKATERIH GLAGOLIH}

Pričujoča študija se ukvarja z majhno skupino večpomenskih glagolov, ki imajo figurativne pomene. Izhajajoč iz teoretičnega pristopa o konceptualni metafori opazujemo semantične težave pri nekaterih glagolskih metaforičnih kombinacijah in pri tem upoštevamo predvsem učence španščine kot tujega jezika. Iz te analize izhajajo opažanja, ki lahko prispevajo $\mathrm{k}$ izboljšanju leksikografske predstavitve polisemičnih glagolov predvsem $\mathrm{v}$ šolskih slovarjih. 